\title{
Failure analysis of Upright \& Base for Shelving Rack
}

\author{
Pratik Vitonde \\ Department of Mechanical Engineering, \\ YCCE, Nagpur, \\ India.
}

\author{
G.H. Waghmare \\ Department of Mechanical Engineering, \\ YCCE, Nagpur, \\ India.
}

\begin{abstract}
Shelving system is used for the display \& storage of Books, Pharmacy products, FMCG goods, electronic goods, canned goods, hardware etc. CAEM is shelving Engineering for the Retail Sector which manufactures modular metal shelving systems for the shop fitting industry. The main structural members of steel storage racks are uprights \& Bases. CAEM India imports upright $\&$ bases from CAEM Italy for shelving racks. In this work, the commercial software, ANSYS, is used for material and geometric nonlinear analysis of the upright $\&$ base and the results are compared with analytical data obtained \& providing a suitable design for the same.
\end{abstract}

Keywords: Analysis; Base; CAEM; Shelving; Upright

\section{INTRODUCTION}

CAEM is Shelving Engineering industry for the Retail Sector having more than fifty years of experience in the manufacturing of modular metal shelving systems. CAEM offers today the widest and most complete and quality oriented shelving system and display solutions for the shop fitting industry. These units are designed to have modularity according to the need of customer, also designed to have interchange-ability as per the requirements. The headquarters is in Italy and the company's direct presence is guaranteed in the UK, in Australia and in India.

CAEM offers display solutions for all retailers, namely: Hyper Markets, Supermarkets, Departmental Stores, Fashion Stores, Consumer Durables, IT and Home Entertainment stores, Specialty stores. They have over the period of last few decades, provided the shelving solutions to many reputed clients located in Europe, Australia, Middle-East, etc The high quality of products along with the continuous development of new \& innovative design solutions gives a strong competitive advantage.[4]

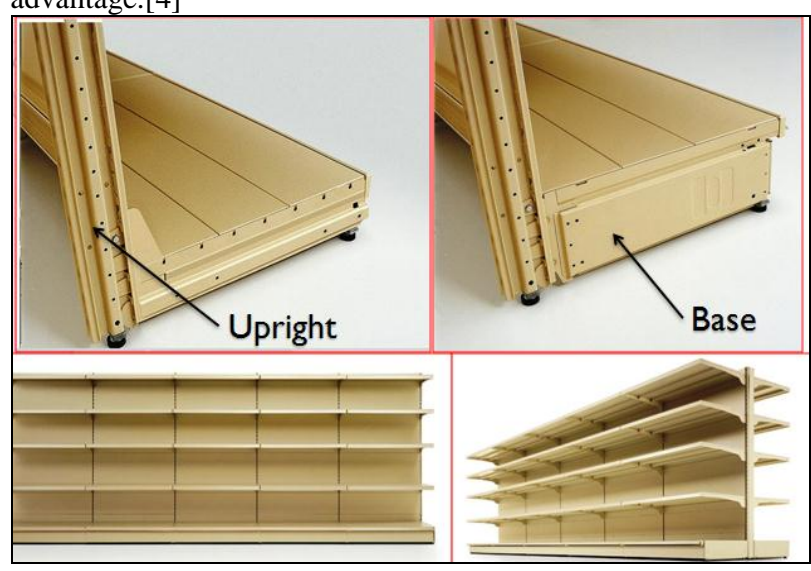

Fig.1 Shelving Rack TN9

CAEM India imports upright \& bases from CAEM Italy for shelving rack system. As the items are imported they are very costly \& also they are difficult to manufacture them in India because of their unique design, number of bends and the special certified high strength steel.

\section{RELATED WORK}

The various points like the dimension, codes and loads that should be specified in order to have a storage rack or shelving system that is economical and safe. The important dimensions to specify are length and width of shelf, and the height between shelves. From the size of the product and pallet, one can determine the depth of the upright or truss. The overhang is required when the shelf beams are not covered with say a sheet of particleboard and the pallet and load could fall between the beams. The upright depth of back to back of column would then be 48 inches minus a total overhang of 4 inches or 44 inches back-to-back of column or rack post. If back-to-back rows are being considered, then one must consider the clearance between loads at the back in order to position the uprights for back-to back rows are length and width of shelf, and the height between shelves. [1]

The product load or shelf load should be always specified. The shelf load will then be used by the shelving supplier to determine the reinforcement, if reinforcing is necessary. Most manufacturers have members such as bars and angles that reinforce the front, back, and side edges; as well as hat shaped sections that reinforce the centre of the shelf by spanning the length the shelf at the centre of the shelf. Failure analysis is an engineering approach to determining how and why equipment or a component has failed. Some general causes for failure are structural loading, wear, corrosion, and latent defects. The goal of a failure analysis is to understand the root cause of the failure so as to prevent similar failures in the future. In addition to verifying the failure mode it is important to determine the factors that explain the "how and why" of the failure event [2].

The main structural members of steel storage rack frames are uprights and pallet beams. While pallet beams brace uprights and provide stiffness against down-aisle buckling through semi-rigid connections to uprights, the most critical members of a rack structure are the uprights, which are usually made from cold-formed open sections. They are the members most affected by instability, including local buckling, distortional buckling. When braced, the spine bracing is accompanied with plan bracing, to also provide down-aisle bracing of the front row of uprights. The down-aisle buckling capacity is affected by the stiffness of the semi rigid connectors (joints) between uprights and pallet beams, and the semi-rigid stiffness of the base plate connection between the upright and floor, of which the latter is dependent on the axial force in the upright[3]. Performance of pallet racking systems depends upon the efficiency of beam-end connectors, which provide, together with column bases, sources of stiffness for downaisle stability. Knowledge of the actual joint behaviour under static and seismic loading is of fundamental importance for a 
suitable definition of simplified moment rotation joint relationships to use into design of semi-continuous frames [4]. Rack systems are very similar to the framed steelworks traditionally used for civil and commercial buildings, but great differences in member geometry and in connection systems. In rack system, the beams are generally boxed crosssection, and columns are open thin walled perforated section to accept the tabs of beam end-connectors [5].

\section{EXISTING UPRIGHT BASE ASSEMBLY}

Initially a design is made as a solution for the TN9 Italian upright \& base as shown in fig- 1 . In this design $80 \times 40 \times 2 \mathrm{~mm}$ thick rectangular pipe section is used for both upright $\&$ base as shown in fig-2. The pipe is cut as per the required dimension for both of the upright $\&$ base. The slotting is done on the upright pipe in such a way that, the pitches of the slots made are compatible with the other assembly items such as backplanes, brackets, and loading bar etc.

A flange of size $75 \times 75 \times 3 \mathrm{~mm}$ thick is welded on the top of the base as shown in the fig-2. The upright is inserted vertically into the flange. The outer dimensions of the flange are smaller than that of the inner dimension of the upright. Once the upright is inserted into the flange the assembly is tightened by the use of fasteners.

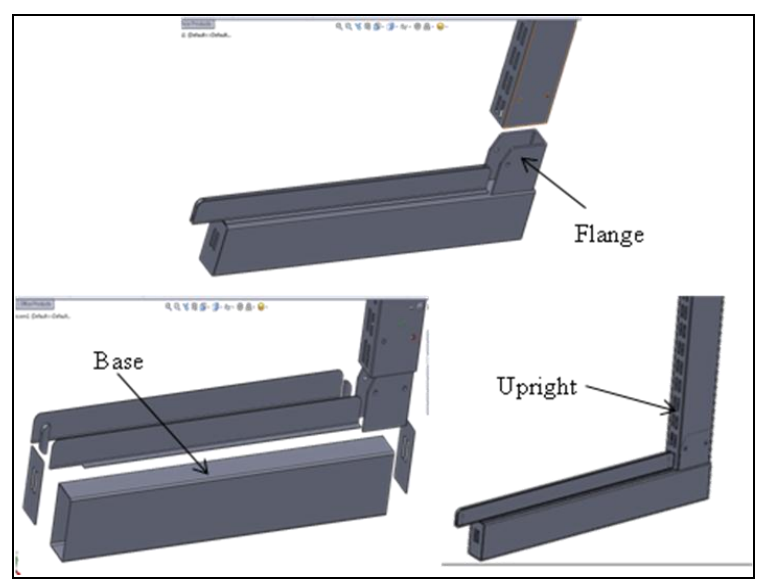

Fig.2 Present Design

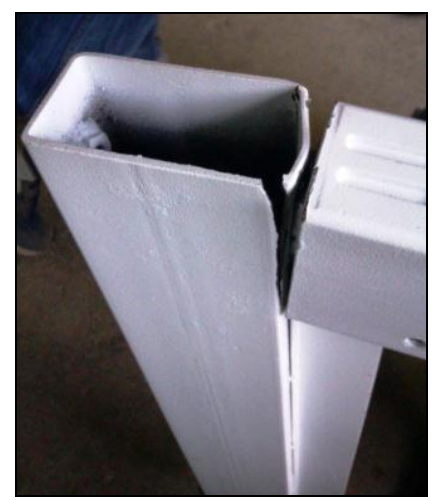

Fig.3 Failure of upright $\&$ base.

The system is put under a specific loading condition for certain duration of time. A test is carried out on it after which it is found that the suggested design for upright $\&$ base is failed as shown in fig-3 on the specific loading condition.
Initial reasons of failures for the suggested design is observed are as follows:

- The load acting on the upright is not going directly towards earth.

- The load acting on the upright is carried by the base.

- The height of base is used as $8 \mathrm{~cm}$ instead of $16 \mathrm{~cm}$ for more than $200 \mathrm{~cm}$ ht. of upright.

- The thickness of pipe section for base \& upright is used as $2 \mathrm{~mm}$ instead of 2.5 to $3 \mathrm{~mm}$ which normally used in other shelving system.

\section{MODIFIED DESIGN}

After identifying the mode of failure in the present design, a modified design is made for the same. In this design, the upright is of full length i.e. up to the ground and the base is inserted to the slot made on the upright. The design has an advantage that the load on the upright is not acting on the base as compare to the present design. The load is directly going to the earth and helps in balancing the overall load acting on the system. The idea is same that of the TN9 system which has similar type of arrangement.

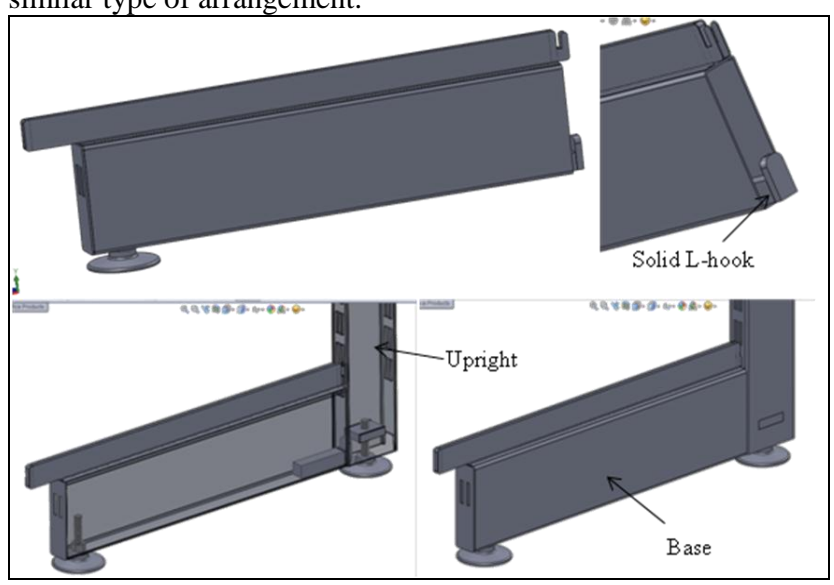

Fig.4 Modified Design

In this, a solid L-hook is welded on the back side bottom of the base pipe as shown in fig-4. The slots are made on the upright pipe in which the L-hook \& top plate brackets are hook tightly. The system is completely modular and there is no need of fasteners to fix the upright base assembly. The rest of the assembly components are made similar to that of present design.

Following are the several advantages of the system \& also the best suited design for the project because:

- The load acting on base \& upright is carried by themselves separately.

- The load acting on the upright is going directly towards earth.

- In the welded option one has to maintain different combinations of uprights $\&$ basses. There are different heights of uprights available i.e. $88 \mathrm{~cm}, 112 \mathrm{~cm}, 120 \mathrm{~cm}$, $134 \mathrm{~cm}$ etc around $25 \mathrm{nos}$. of sizes. \& different depths of 
bases available i.e. $20 \mathrm{~cm}, 30 \mathrm{~cm}$ up to $80 \mathrm{~cm}$. around 8nos. of sizes.

- So if the welding option is used their will be ' $n$ ' number of combinations of upright $\&$ bases. In this case it is very difficult to maintain the separate stock of upright $\&$ bases combinations in warehouse which will directly leads to fatigue \& increase is in inventory cost.

- In case of option one it is difficult to weld the flange perpendicular on the top of the upright. If the welding is not done properly the misalignment will be their \& will be difficult for the assembly.

- Completely modular system.

- No need of fasteners.

- Simple assembly \& saves time for the installation.

\section{Material \& Design for maximum load}

Material: the Material for upright \& base I.S. C-30 Soft Steel (SAE1030) material used is.

Table 1. Material and Their Properties

\begin{tabular}{|c|c|c|c|c|c|c|c|}
\hline Material & $\mathbf{S}_{\mathbf{u t}}$ & $\mathbf{S}_{\mathbf{y t}}$ & $\mathbf{S}_{\mathbf{y e}}$ & $\mathbf{S}_{\mathbf{e b}}$ & $\mathbf{E}$ & $\mathbf{G}$ & $\mathbf{B H N}$ \\
\hline $\begin{array}{c}\text { I.S. C-25 } \\
\text { Soft Steel } \\
\text { (SAE } \\
1025)\end{array}$ & 455 & 232 & 136 & 198 & 204 & 80 & 120 \\
\hline $\begin{array}{c}\text { I.S. C-30 } \\
\text { Soft Steel } \\
\text { (SAE } \\
1030)\end{array}$ & 527 & 296 & 183 & 225 & 204 & 79 & 150 \\
\hline $\begin{array}{c}\text { I.S. C-30 } \\
\text { Soft Steel } \\
\text { (SAE } \\
\text { 1035) }\end{array}$ & 580 & 367 & - & - & 204 & 79 & 126 \\
\hline
\end{tabular}

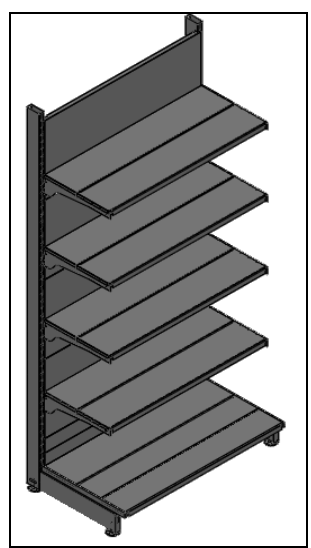

Fig.5 Assembly of designed unit

Loading Condition: - For the project work the upright height is selected as $208 \mathrm{~cm} \&$ base depth as $50 \mathrm{~cm}$. This combination is widely used in the supermarkets, big bazaar, hypermarkets etc. Fig-6 shows the detail structure for the system. The unit has 4 shelf of size L$40 \mathrm{~cm}$. A uniformly distributed load of $55 \mathrm{~kg}$ is used for per shelves. $80 \times 30 \times 2.5 \mathrm{~mm}$ thick rectangular pipe section is used for upright \& $100 \times 80 \times 2.5 \mathrm{~mm}$ thick section for base.

After doing little iteration on loading, the load $540 \mathrm{~N}$ is found safer for the system as described below:

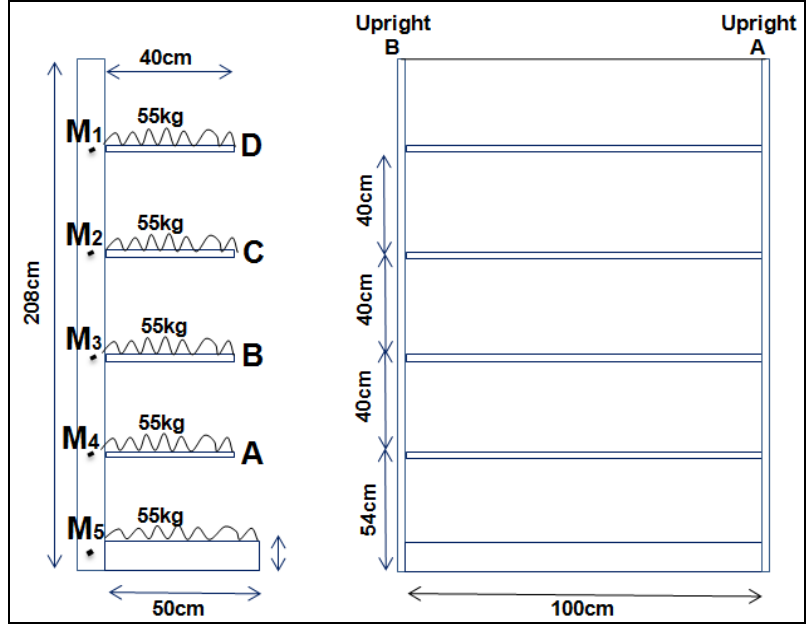

Fig.6 Loading condition

\section{$\underline{\text { Reaction at } \mathbf{A}}$}

$\mathrm{Ra}=540 \times 0.4 \quad \mathrm{Ra}=216 \mathrm{~N}$

\section{Shear Force}

$$
\begin{aligned}
& A=R a=216 N \\
& C=216 N \\
& B=216-(540 \times 0.4)=0
\end{aligned}
$$

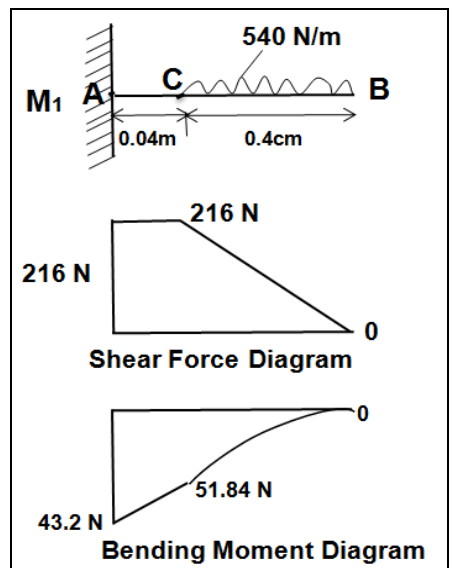

Fig.7 Shear force \& Bending Moment Diagram

\section{Bending Moment,}

$$
\begin{aligned}
& \Sigma \mathrm{M}_{\mathrm{x}}=0 \\
& \mathrm{M}_{\mathrm{b}}=0 \\
& \mathrm{M}_{\mathrm{c}}=-43.2 \mathrm{~N}-\mathrm{m} \\
& \mathrm{M}_{\mathrm{a}}=-51.84 \mathrm{~N}-\mathrm{m}
\end{aligned}
$$

Now, $\mathrm{M}_{2}=\mathrm{M}_{1}+\mathrm{M}_{2}=-72.576 \mathrm{~N}-\mathrm{m}$

$\mathrm{M}_{3}=\mathrm{M}_{1+} \mathrm{M}_{2}+\mathrm{M}_{3}=-122.34 \mathrm{~N}-\mathrm{m}$

$\mathrm{M}_{4}=\mathrm{M}_{1}+\mathrm{M}_{2}+\mathrm{M}_{3}=-221.04 \mathrm{~N}-\mathrm{m}$ 
$\mathrm{M}_{5}=\mathrm{M}_{1}+\mathrm{M}_{2}+\mathrm{M}_{3}+\mathrm{M}_{4}=-420.36 \mathrm{~N}-\mathrm{m}$

$\frac{M}{I}=\frac{\sigma b}{Y}=\frac{E}{R}$

$\sigma b=\frac{M}{Z}$

$\frac{I}{Y}=Z$ i.e. Section Modulus

For rectangular cross-section,

$$
\begin{aligned}
& I=\frac{B D^{3}}{12}-\frac{b d^{3}}{12} \\
& I=\frac{1}{12}\left(B D^{3}-b d^{3}\right)
\end{aligned}
$$

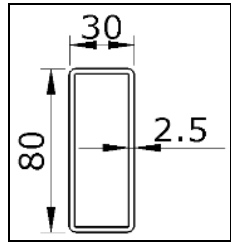

\section{Fig.8 Cross-section of upright}

\section{$I=82.34 \times 10^{3} \mathrm{~mm}^{4}$}

$Y=\frac{D}{2}$

\section{$\mathrm{Y}=40 \mathrm{~mm}$}

\section{$\sigma b=205 \mathrm{Mpa}$}

Allowable Bending stress $\mathrm{S}_{\mathrm{eb}}=225 \mathrm{Mpa}$

$\boldsymbol{\sigma b}=205 \mathrm{Mpa}<$ Allowable Bending stress Design is

Safe

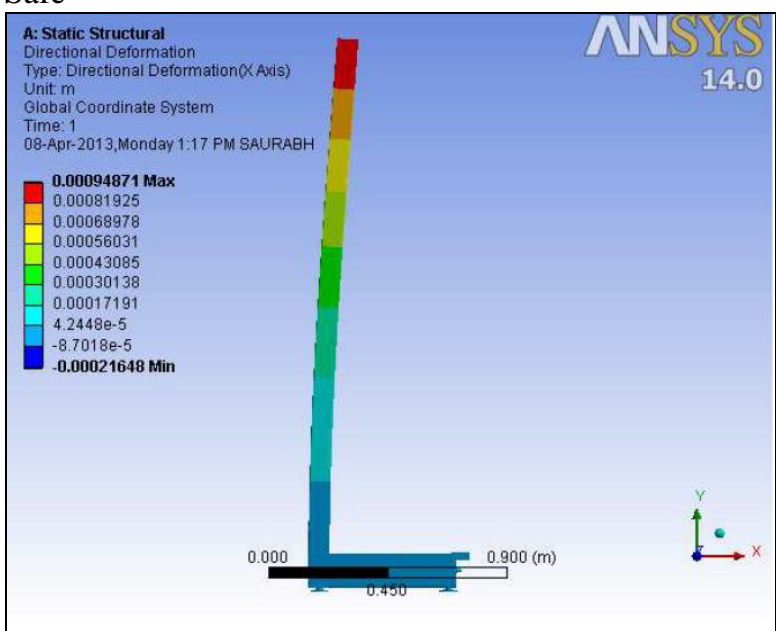

Fig.9 Structural analysis of upright base assembly at $490 \mathrm{~N}$

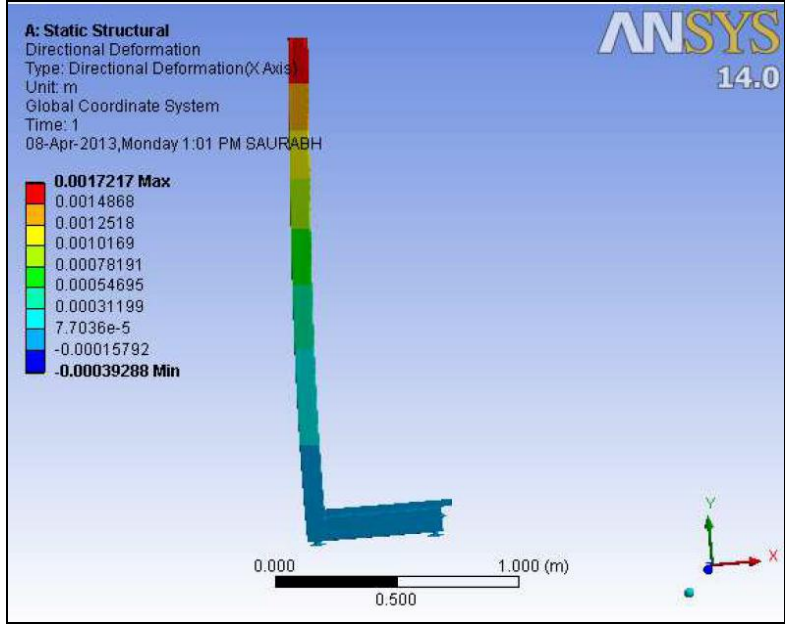

Fig.10 Structural analysis of upright base assembly at $270 \mathrm{~N}$

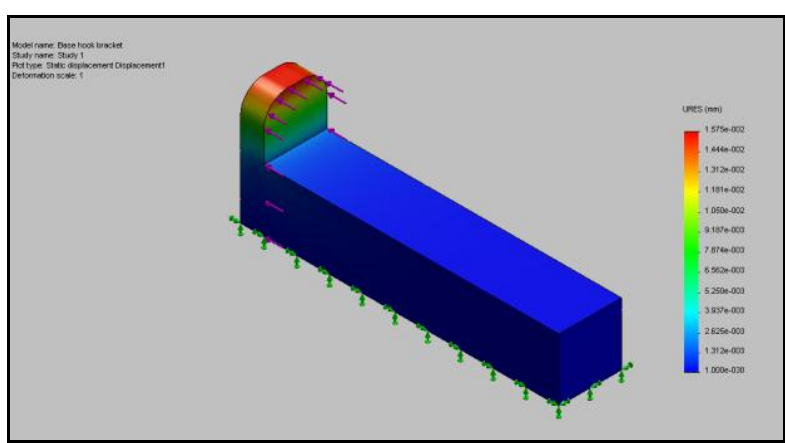

FIG.11 STRUCTURAL ANALYSIS OF BASE PLATE

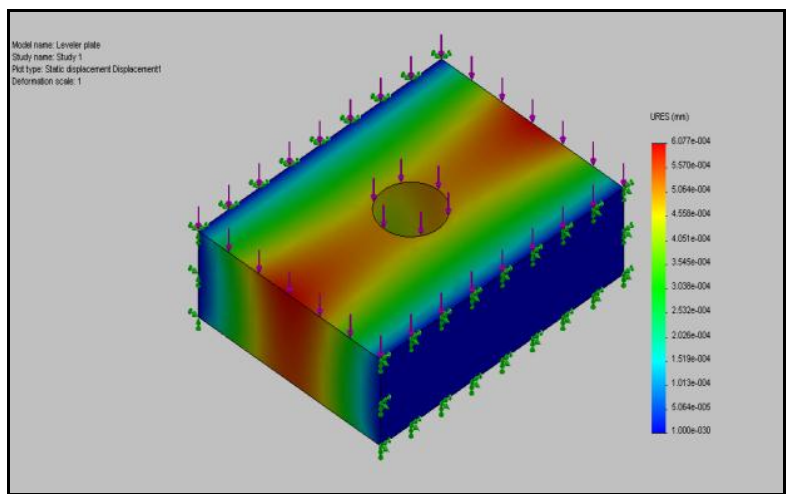

Fig.12 Structural analysis of Leveler plate

\section{NOMENCLATURE}

$\boldsymbol{\sigma b}$ - Bending stress Mpa

I - Moment of inertia mm4

$\mathrm{Z}$ - Section modules mm3

$\mathrm{M}$ - Bending Moment N-mm

$\mathrm{Y}$ - Distance from neutral axis $\mathrm{mm}$

$\mathrm{R}$ - Radius of curvature

$\mathrm{S}_{\mathrm{ut}}$ - Ultimate tensile strength Mpa

$\mathrm{S}_{\mathrm{yt}}$ - Yield strength in tensile Mpa

$\mathrm{S}_{\mathrm{ys}}$ - Yield strength in shear Mpa

$\mathrm{S}_{\mathrm{eb}}$ - Endurance limit in reversed bending Mpa 


\section{CONCLUSION}

The main aim of the project is to carry the specified load by the upright $\&$ base assembly as long as possible. The existing arrangement is quite unable to carry the specified loading condition thus we modified the assembly. The new modified assembly for upright $\&$ base has given the better result than the existing one. The new suggested material \& extra thickness for upright $\&$ base will improve its hardness and working efficiency at $540 \mathrm{~N}$ and minimizes the bending \& failure of the upright $\&$ base.

\section{ACKNOWLEDGMENTS}

I would like to give my sincere thanks to the whole CAEM group, who provided tremendous support, knowledge and encouragement and had the trust in my capability to the conduct the research of this nature.

\section{REFERENCES}

[1] W.R. Midgley, "Planning \& Engineering Guidelines for Specifying Storage Racks and Shelving Systems".Principal Midgley-Clauer Associates, INC.4438 Lleffingwell Road Canfield, Ohio 44406.NA 92 Forum.

[2] TCR Engineering Services Technical Team, "Investigating Material \& Component Failure", published July- 2004. K.J.R. Rasmussen \& B.P. Gilbert, "Analysis-based design provisions for steel storage racks", School of Civil Engineering, University of Sydney, Sydney NSCC2009.

[3] K.J.R. Rasmussen \& B.P. Gilbert, "Analysis-based design provisions for steel storage racks", School of Civil Engineering, University of Sydney, Sydney NSCC2009.

[4] Nadia Baldassino,Claudio Bernuzzi, Riccardo Zandonini, "PERFORMANCE OF JOINTS IN STEEL STORAGE PALLET RACKS", Department of Mechanical and Structural Engineering, University of Trento

[5] K.M. Bajoria, K.K. Sangle, "DYNAMIC ANALYSIS OF 2-D AND 3-D COLD FORMED STORAGE RACK STRUCTURES WITH RIGID AND SEMI RIGID CONNECTIONS" Associate Professor Department of Civil Engineering, Indian Institute of Technology Bombay, Powai, Mumbai- 400076 (India). The 14th World Conference on Earthquake Engineering October 12-17- 2008, Beijing, China.

[6] B.D. Shiwalker, "Desigk data book for machine elements" (S.I. Units) 22nd Jun 2008.

[7] www.caem.net,www.youtube.com/wwwcaemnet,www.f acebook.com/caem.net 